\title{
Multicentric cutaneous \\ Crohn's disease: A case report and review of literature
}

\author{
Robert Prokopetz, MD, FrCPC, J Barrie Ross, MD, FRCPC, PeTER SMITH, MD, FRCPC, \\ JOSEPH J SIDOROV, MD, FRCPC
}

ABSTRACT: A patient presented with skin lesions at sites not contiguous with Cro' 2 's disease of the bowel and with specific histological features of Crohn's disease occurring two weeks from the onset of bowel symptoms. Currently a number of nonspecific skin conditions such as erythema nodosum, pyoderma gangrenosum and erythema multiforme are accepted as being the most common skin manifestations of Crohn's disease. It is likely, however, that specific lesions of Crohn's disease in the skin have been underdiagnosed either because of lack of biopsy or misinterpretation of the histology. Twenty-three cases with specific Crohn's disease in the skin have been recorded in the past 25 years, since the condition has been recognized. Sarcoidosis has been a common misdiagnosis. The literature relating to multicentric Crohn's disease is reviewed and attention drawn to its protean and masquerading features. An argument is made for the use of the term 'multicentric' rather than 'metastatic' in relation to cutaneous Crohn's disease. Can J Gastroenterol 1990;4(2):59-63

Key Words: Crohn's disease of skin, Metastatic Crohn's disease, Multicentric Crohn's disease

\section{Maladie de Crohn multicentrique: Observation et revue de la littérature médicale}

RESUME: Une patiente atteinte de maladie de Crohn a présenté des lésions cutanées à des sites non contigus aux segments pathologiques de son intestin; les caractéristiques histologiques spécifiques de la maladie de Crohn se sont manifestées deux semaines après le début des symptômes intestinaux. Présentement, un certain nombre d'affections cutanées non spécifiques -

Divisions of Dermatology and Gastroenterology, Department of Medicine, Dalhousie University, Halifax, Nova Scotia

Correspondence and reprints: Dr JJ Sidorov, 5991 Spring Garden Road, Suite \#645, Halifax, Nova Scotia B3H IY6. Telephone (902) 423-8239

Received for publication August 23,1989. Accepted November 17, 1989
S KIN IS THE MOST COMMON SITE OF extraintestinal manifestations of Crohn's disease. These cutaneous manifestations can be divided into nongranulomatous and granulomatous lesions (1). The common nongranulomatous lesions are erythema nodosum, erythema multiforme and pyoderma gangrenosum. The most usual forms of granulomatous inflammation are contiguous perianal, perifistular or peristomal extension of the bowel disease, with a reported incidence of up to $47 \%$ in Crohn's colitis (2).

'Metastatic Crohn's disease', defined as cutaneous granulomatous lesions separated from the bowel, the fistula or stomal opening by normal intervening skin (3), has been only occasionally reported.

The authors have had the opportunity to observe initially and follow for four years a patient with such cutaneous lesions and intermittent arthralgia.

\section{CASE REPORT}

A 32-year-old white female was admitted on November 10, 1985 for investigation of a possible rectovaginal fistula. She had been well all her life 
érythème noueux, pyoderma gangrenosum et érythème polymorphe-sont reconnues comme appartenant aux manifestations cutanées les plus courantes de la maladie de Crohn. Il est toutefois probable que les manifestations cutanées révélatrices de cette maladie demeurent souvent sous-diagnostiquées; cette situation s'explique soit par l'absence de biopsie soit par des interprétations histologiques erronées et c'est sans doute pourquoi 23 cas seulement de maladie de Crohn avec manifestations cutanées spécifiques ont été relevés au cours des 25 dernières années qui se sont écoulées depuis que cette condition est connue. La sarcoïdose est une erreur de diagnostic courante. Les publications portant sur la maladie de Crohn multicentrique sont passées en revue et l'accent porte sur ses caractéristiques protéiformes et trompeuses. On préconise l'usage du terme 'multicentrique' plutôt que 'métastatique' pour qualifier la maladie de Crohn cutanée.

except for the repair of an anal fissure and a hemorrhoidectomy in 1982. She had had two normal pregnancies with normal deliveries. She had been taking oral contraceptives for the past 12 years.

Early in October 1985 she noticed increased bowel frequency, usually precipitated by meals. This progressed gradually to five loose and watery bowel movements daily. Over the next two weeks mucus and bright red blood appeared. She developed a sensation of rectal fullness and burning followed by fever and chills, requiring admission to a local hospital where a large ischiorectal abscess was drained. Her symptoms persisted despite treatment with sulfasalazine.

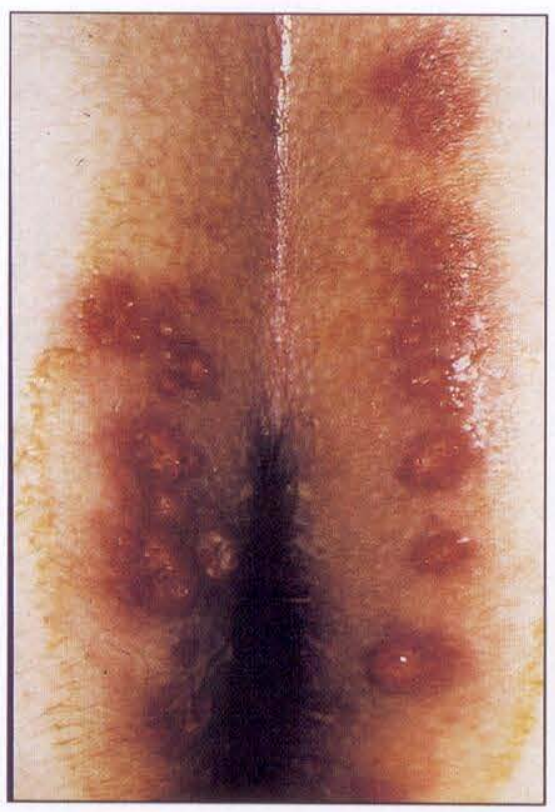

Figure 1) Vulval lesions
In the two weeks prior to admission the patient developed painless, blisterlike, erythematous and slightly papular lesions approximately $1 \mathrm{~cm}$ in diameter, involving the skin of her arms, face, chest, abdomen and legs. Some of these developed central umbilication with surrounding hemorrhage. Most of them cleared eventually, with mild scarring. She also developed painful aphthous ulceration of the mouth and vagina associated with mild fever and chills.

On admission she was afebrile and in moderate distress due to pain in the perianal region. General physical examination was normal apart from skin and mucous membranes. The mucosal surface of the left side of the lower lip

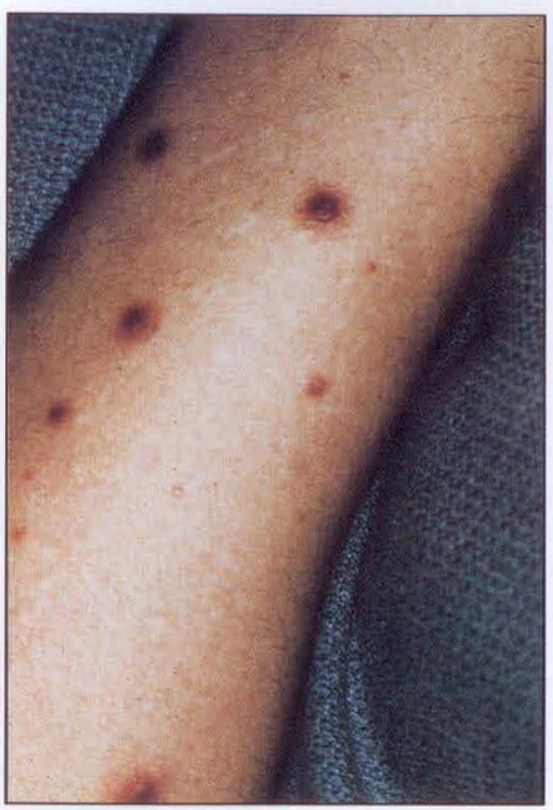

Figure 2) Lesions on arm

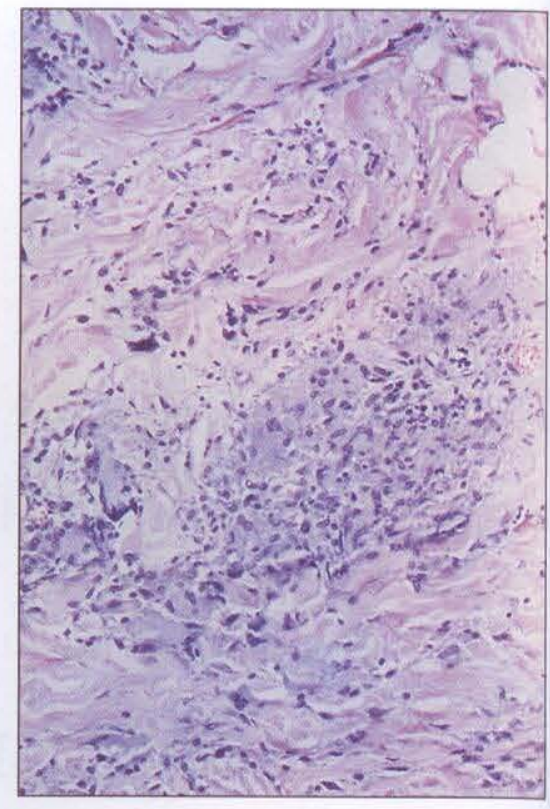

Figure 3) Lesion from arm showing typical granuloma with lymphocytes, epithelial his. tiocytes and multinucleate giant cells

showed a superficial ulcer approximately $1.5 \mathrm{~cm}$ in greater diameter, with an erythematous, indurated border. The intergluteal cleft, perianal area, perineum and vulva showed extensive discrete ulcerations (Figure 1). There were papular lesions scattered randomly over the arms, legs, trunk and buttocks (Fig. ure 2 ). Some of the papules and nodules showed central ulceration producing an umbilicated surface covered with a hemorrhagic crust.

Lesions from the buttock and left leg were biopsied and both showed central necrosis and ulceration of the epidermis and upper dermis. The surrounding dermis showed numerous lymphocytes, epithelial histiocytes and multinucleated giant cells which, in areas, formed small granulomas (Figure 3). Stains for acid-fast bacilli and fungi were negative.

The patient was examined by sig. moidoscopy under anesthesia and was found to have a rectovaginal fistula. An upper gastrointestinal series and small bowel follow through showed no abnormalities. Hemoglobin was $116 \mathrm{~g} / \mathrm{L}_{\text {i }}$ white blood cell count $12,800 / \mathrm{mm}^{3}$ with $59 \%$ granulocytes, $16 \%$ band forms and $17 \%$ lymphocytes; albumin was $26 \mathrm{~g} / \mathrm{L}$. The standard routine investigations were normal. Sulfasalazine 


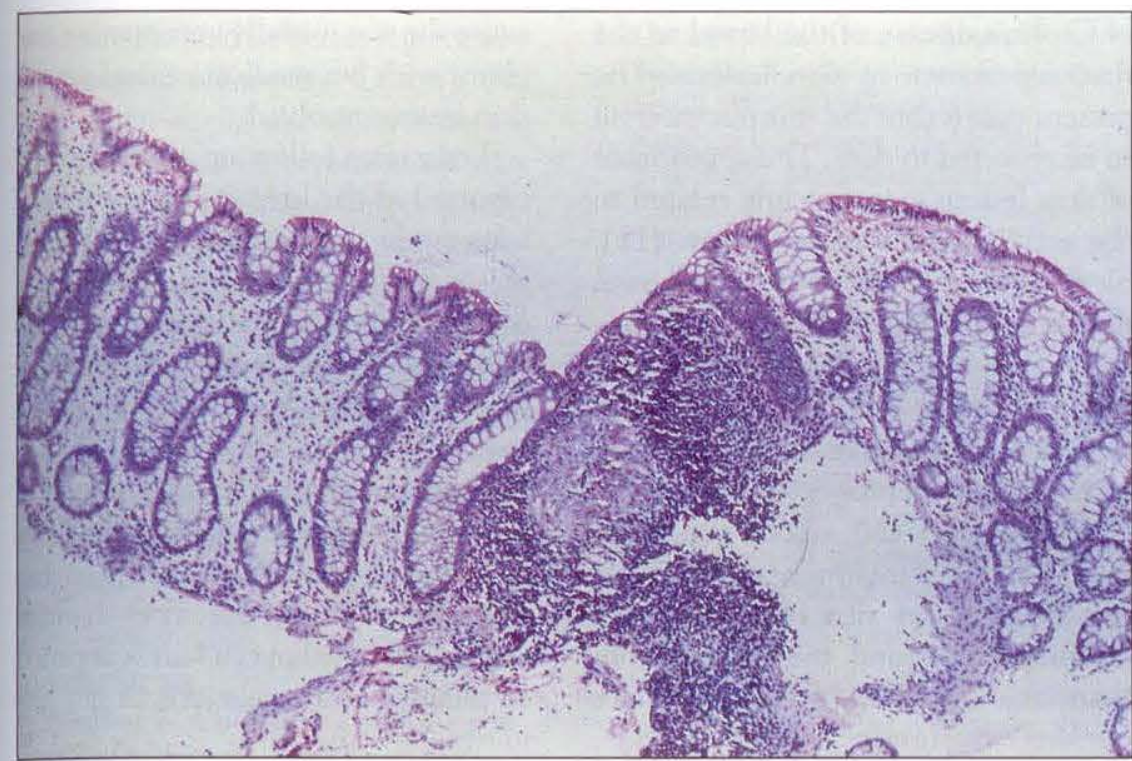

Figure 4) Biopsy of cecum showing acute inflammatory change and epithelioid granuloma consistent with Crohn's disease

was discontinued and the patient was treated with metronidazole $500 \mathrm{mg}$ every $6 \mathrm{~h}$ and placed on an elemental diet. She refused all further investigation including barium enema and was discharged on November 21, 1985.

She was readmitted on December 3 , 1985 with migratory swelling and tenderness of the small joints, knees and elbows as well as symptoms of dryness and foreign body sensation of the eyes. She had not been taking the metronidazole prescribed on a recent admission. She had two or three soft bowel movements per day without blood or mucus. The intergluteal, perianal and perineal ulcerations had cleared. The rectovaginal fistula was no longer detectable. The majority of the previously present skin lesions were resolving, but a few new lesions had appeared about the arms. Most of these were hyperpigmented macules without significant scarring. A few new erythematous nodules were present on the upper arms, one of which was biopsied. The histology showed prominent patchy inflammation involving all layers of the dermis with the greatest involvement in the reticular dermis.

The deepest part of the biopsy was necrotic. In the reticular dermis there were one or two epithelioid granulomas. Special stains for acid-fast bacilli and fungi were negative. Culture for
Mycobacterium tuberculosis grew no organisms (Figure 3).

The patient refused aspiration of the swollen knee joints, and the multiple effusions subsequently disappeared. Eye examination was normal and the symptoms subsided.

A colonoscopic examination demonstrated irregularly inflamed mucosa with linear ulcerations involving the cecum. The sigmoid colon showed nonspecific acute and chronic inflammation. Biopsy of the cecum showed mild acute inflammation related to crypt structures with an epithelioid granuloma consistent with Crohn's disease (Figure 4). Laboratory investigations showed an erythrocyte sedimentation rate of $104 \mathrm{~mm} / \mathrm{h}$. The lupus erythematosus cell preparation, serum complement levels, antimitochondrial antibodies, antinuclear antibodies, rheumatoid factor, Mantoux (five tuberculosis units), and chest $\mathrm{x}$-ray examination were all negative or normal. She was treated with prednisone $60 \mathrm{mg}$ daily, and azathioprine $100 \mathrm{mg}$ daily followed by gradual reduction and tapering of the dose until it was discontinued two weeks after discharge.

The patient was discharged home but returned two months later because of a perianal abscess that required surgical drainage. She had also developed swelling with effusion in the right knee joint which promptly cleared up on reinstitution of treatment with azathioprine and oral prednisone. By August 1986 perianal drainage had stopped completely and the patient was asymptomatic.

Over the next three years she had two more episodes of symptomatic clinical relapse (increased bowel frequency, abdominal cramps, recurrent swelling of the right knee and drainage from perianal fistula). These episodes responded to treatment with prednisone. Her cutaneous lesions remained quiescent throughout and the prednisone was tapered off. Colonoscopy had been performed in April 1989. In May 1989, she was asymptomatic and showed localized areas of redness and friability with a few scattered aphthous ulcerations in the cecum and midsigmoid colon. Histology revealed inflammatory changes with distortion of the crypts and Paneth cell metaplasia. When last seen on August 16, 1989 she had no symptoms except for an occasional ache in the right knee and was taking no medication.

\section{DISCUSSION}

'Metastatic' Crohn's disease is a rarely reported cutaneous manifestation of Crohn's disease.

The first two patients were reported by Parks and colleagues in 1965 (4). Their first case was that of a 70-year-old female with Crohn's disease and an ulcer under her right breast which showed a 'sarcoidal granulomatous reaction'. The second case was a man with Crohn's disease and a penile ulcer, also showing a granulomatous reaction. The authors comment that the skin lesions distantly removed from the diseased bowel were of 'the nature of metastasis'.

Mountain (3) was the first to define the criteria for 'metastatic' skin lesions and to recognize that granulomatous involvement of the skin could be seen in periorificial, peristomal or 'metastatic' skin locations.

Over the years a further 21 patients (11 males and 12 females) with 'metastatic' Crohn's disease have been described. The age range has been from 
16 to 70 years, with a mean age of 39.8 . In most cases the race of the patient has not been specified, but there have been at least one Chinese (5) and two black patients $(6,7)$.

Cutaneous lesions have been reported on widespread areas of the body. Initially the lesions were thought to be confined to intertriginous sites $(3,4,8-10)$, but later lesions were found also in nonintertriginous areas of the skin (6,11-14). In slightly more than one-quarter of cases, lesions occurred on more than one anatomical region, while the remainder were confined to a single anatomical site, the most common being the external genitalia ( $26 \%$ of cases), followed by the trunk (17\%), with the upper limbs, lower limbs, and head and neck being less frequently and approximately equally involved.

Cutaneous lesions have shown great variety of appearance, ulcers being the most common $(3,4,15-17)$. Nodules $(9,11-12,18)$ have also been frequently described. Edema or induration $(5,19)$, plaques (13), vesicles (13), papules $(12,14)$, and 'granulomatous' lesions (8) have been described less frequently. One patient presented with an erysipelas-like lesion of the face (14).

Histologically all cases have shown noncaseating, sarcoid-like granulomas. In some cases the granulomas were closely related to dermal or subcutaneous blood vessels $(11,12,18)$, while in others they were present randomly throughout the dermis $(5,7,9,14,17,20)$ or in both the dermis and the subcutis $(13,14,19,21)$.

The present patient, in common with all previously reported cases, had inflammatory disease involving the large bowel. This has been shown to be associated with a high incidence of extraintestinal manifestations of presumed immunological nature (23). Patients showing ileitis alone have not been reported to show multicentric skin lesions.

There have been no reports to date of skin lesions preceding the bowel symptoms. In the present patient the skin lesions followed the onset of bowel symptoms by only two weeks. Reports in the literature give a range of two months to 19 years from the diagnosis of Crohn's disease of the bowel to the first appearance of skin lesions. The present case is thus the shortest interval to be reported to date. The appearance of skin lesions is not clearly related to the activity of the bowel disease (12). Skin lesions occurred when the bowel disease was 'asymptomatic' or 'controlled' in eight of the 22 patients $(6,7,11,12,14,16)$, and have also been reported in patients who had a previous total proctocolectomy $(3-6,16)$.

Reports on the effectiveness of various forms of treatment are conflicting because of the lack of exact documentation and the use of more than one modality of treatment per patient. Systemic corticosteroids, either alone or in combination with other agents, have been the most frequently used treatment $(3,7,12,13$, 17,19-21). They have been reported as both effective $(12,13,17)$ and ineffective (19). Intralesional corticosteroids were effective in one case (13). One patient with an erysipelas-like eruption on the face responded to topical fluorinated corticosteroids (14). Sumathipala (16) also reported a response to topical fluorinated corticosteroids while Cockburn (19) found them ineffective.

Sulfasalazine has been the next most extensively used agent. Four patients reported in the literature were already on this drug when the skin lesions appeared $(9,11,18,19)$, and in none could a beneficial response be attributed to the drug.

Other forms of treatment have been reported in individual cases including dapsone (12), azathioprine (8), oral zinc (4) and 6-mercaptopurine (4). However, as these are individual case reports, the results are difficult to assess. Systemic antibiotics have not been consistently effective. Surgical treatments including repeated curettage (3) and extensive resection of lesions involving the genitalia $(5,6,17)$ appear to have been effective.

Spontaneous remission has occurred without any active treatment (14) and it is possible that this occurred in other cases although treatment was given to the patients $(7,8,11,18)$. The present patient may fall into this category be- cause she was initially very poorly compliant with her medication and yet the skin lesions resolved.

Long term follow-up of the patients reported in the literature has not been adequately documented to allow reliable conclusions of the natural history of the lesions. The course and behaviour of the lesions are unpredictable. Some have had long term remission of skin disease $(6,11,14)$ on or off treatment, but others continue to have either persistent lesions or clumps of recurrent lesions $(12,13)$. In the present patient the skin lesions remained healed over a four year period of relapses and remissions of gut and joint symptoms.

'Metastatic' cutaneous involvement in Crohn's disease is probably much more common than the literature indicates, being underdiagnosed through a low index of suspicion. Skin lesions may be overlooked as trivial or nonspecific, or may be misdiagnosed as other conditions. Burgdorf (1) has called 'metastatic Crohn's disease' still another great imitator, and he describes many conditions, such as cutaneous vasculitis, with which it has been confused. Thus any unexplained skin eruption in a patient with inflammatory bowel disease should be examined critically and biopsied for the characteristic granulomatous infiltrate. It is only in this way that the true incidence of cutaneous involvement in Crohn's disease will be fully appreciated.

While Crohn's disease occurs predominantly in the terminal ileum or the colon, it may occur in more proximal parts such as the more proximal small bowel, stomach, esophagus and even the oral cavity. It is frequently associated with involvement of extraintestinal structures such as skin, joints (22), eyes (23), blood vessels (11), muscles (9), and liver (24). The tendency to involve the terminal ileum and colon predominantly remains unexplained.

The term 'metastatic' may be inap. propriate, as it implies distant spread from a given site. The skin lesions present more as a concurrent manifes. tation of multisystem involvement with inflammatory bowel disease. The term 
'metastatic' would be better replaced by 'multicentric cutaneous' Crohn's disease, which would also differentiate it from contiguous involvement. It may be that further study and longer followup of patients will provide more information as to why these lesions occur in only certain patients with Crohn's disease. It might be speculated that local factors such as trauma, vascular supply, chemical, physical or infective factors or more general ones such as a change in immune status - may play a role in defining the site of the lesions.

\section{REFERENCES}

1. Burgdorf W. Cutaneous manifestations of Crohn's disease. J Am Acad Dermatol 1981;5:689-95.

2. Rankin GB, Watts HD, Melnyk CS, Kelley ML Jr. National cooperative Crohn's disease study: Extraintestinal manifestations and perianal complications. Gastroenterology 1979;77:914-20.

3. Mountain JC. Cutaneous ulceration in Crohn's disease. Gut 1970;11:18-26.

4. Parks AG, Morson BC, Pegum JS. Crohn's disease with cutaneous involvement. Proc R Soc Med 1965;58:241-2.

5. Ansell ID, Hogbin B. Crohn's disease of the vulva. J Obstet Gynecol Br Common 1973;80:376-8.
6. Goolamali SK, Price A. Extensive cutaneous Crohn's disease. Br J Dermatol 1983;109 (Suppl 24):86-7.

7. Sutphen JL, Cooper PH, Mackel SE, Nelson DL. Metastatic cutaneous Crohn's disease. Gastroenterology 1984;86:941-4.

8. McCallum DI, Gray WM. Metastatic Crohn's disease. Br J Dermatol 1976;95:551-4.

9. Witkowski JA, Parish LC, Lewis JE. Crohn's disease - Noncaseating granulomas on the legs. Acta Derm Venereol Suppl (Stockholm) 1977;57:181-3.

10. McCallum DI, Kinmont PDC. Dermatological manifestations of Crohn's disease. $\mathrm{Br}$ J Dermatol 1968;80:1-8.

11. Burgdorf W, Orkin M. Granulomatous perivasculitis in Crohn's disease. Arch Dermatol 1981;117:674-5.

12. Chalvardjian A, Nethercott JR. Cutaneous granulomatous vasculitis associated with Crohn's disease. Cutis 1982;30:645-55.

13. Levine N, Bangert J. Cutaneous granulomatosis in Crohn's disease. Arch Dermatol 1982;118:1006-9.

14. Lebwohl M, Fleischmajer R, Janowitz $\mathrm{H}$, Present D, Prioleau PG. Metastatic Crohn's disease. J Am Acad Dermatol 1984;10:33-8.

15. Kao MS, Paulson JD, Askin FB. Crohn's disease of the vulva. Obstet Gynecol 1975;46:329-33.
16. Sumathipala AHT. Penile ulcer in Crohn's disease. J R Soc Med 1984;77:966-7.

17. Tweedie JH, McCann BG. Metastatic Crohn's disease of thigh and forearm. Gut 1984;25:213-4.

18. Liebermann TR, Greene JF. Transient subcutaneous granulomatosis of the upper extremities in Crohn's disease. Am J Gastroenterol 1979;72:89-90.

19. Cockburn AG, Krolikowski J, Balogh K, Roth RA. Crohn's disease of penile and scrotal skin. Urology 1980;15:596-8.

20. Tatnall FM, Dood HJ, Sarkany I. Crohn's disease with metastatic cutaneous involvement and granulomatous cheilitis. J R Soc Med 1987;80:49-51.

21. Phillips RKS, Glazer G. Metastatic Crohn's disease of the umbilicus. $\mathrm{Br}$ Med J 1981;283:887.

22. Frayha R, Stevens MB, Bayless TM. Destructive monoarthritis and granulomatous synovitis as the presenting manifestations of Crohn's disease. John Hopkins Med J 1975;137:151-5.

23. Korelitz B, Coles R. Uveitis (iritis) with ulcerative and granulomatous colitis. Gastroenterology 1967;52:7882.

24. Sidorov JJ. The protean complications of IBD. In: deDombal FT, Myren J, Bouchier IAD, Watkinson G, eds. IBD, Some International Data and Reflections. Oxford: Oxford University Press , 1986:161-246. 


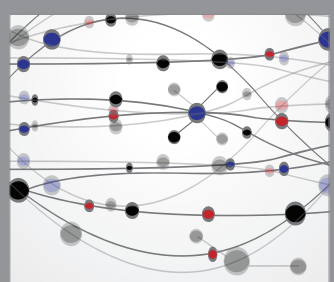

The Scientific World Journal
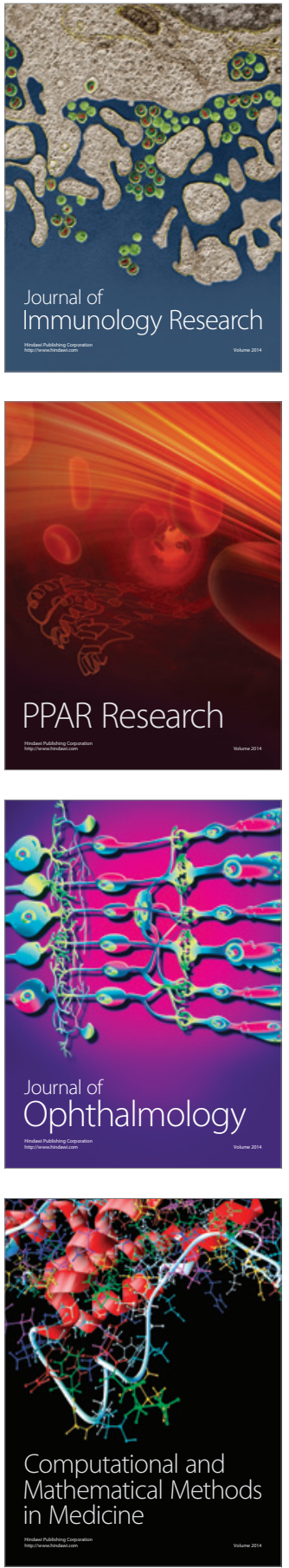

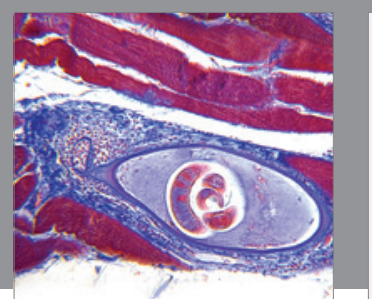

Gastroenterology Research and Practice

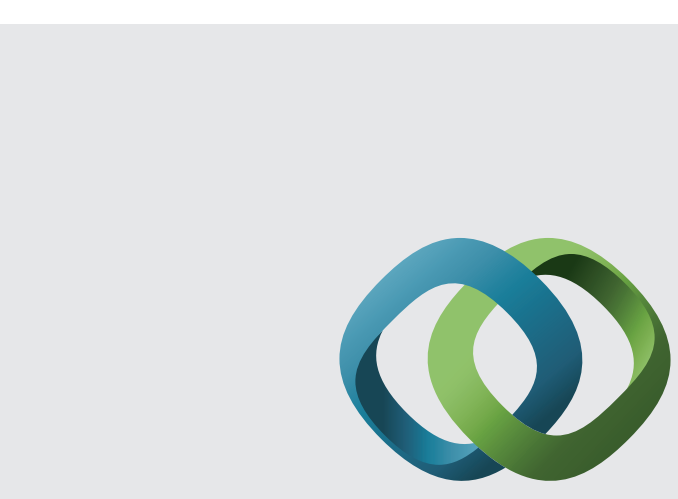

\section{Hindawi}

Submit your manuscripts at

http://www.hindawi.com
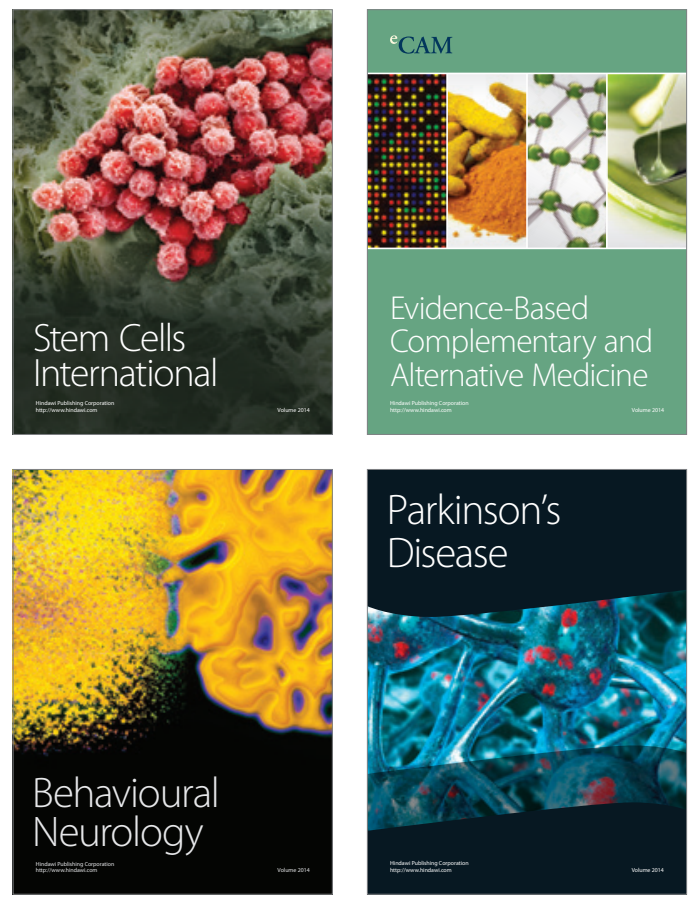
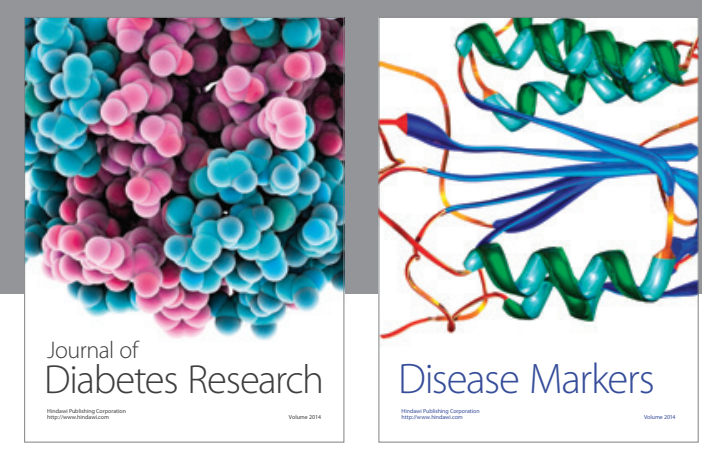

Disease Markers
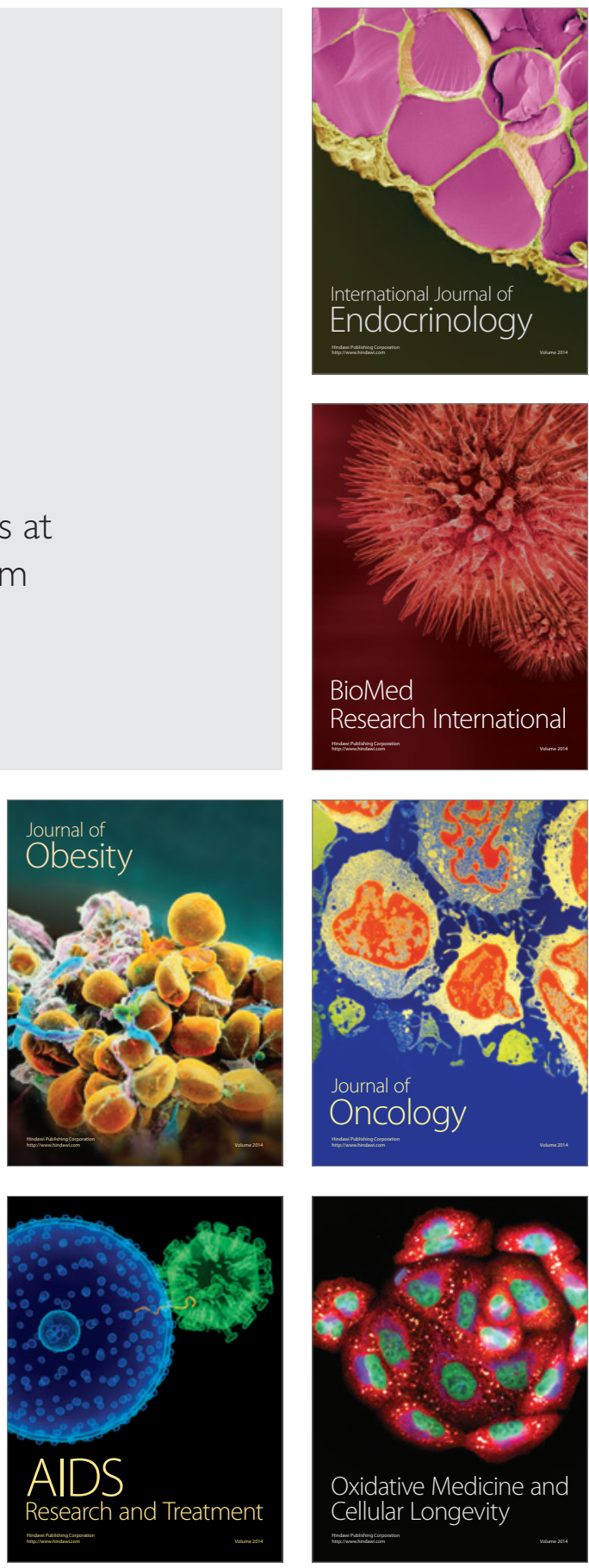